\title{
Long-Term Outcomes After St. Jude Medical Mechanical Valve Implantation
}

\author{
Wataru Tatsuishi, MD; Kiyoharu Nakano, MD, PhD
}

$\mathbf{T}$ he St. Jude Medical (SJM) mechanical valve is a bileaflet valve that is constructed using pyloric carbon to achieve the concept of "one valve in one life." Since its development in 1977, the SJM valve has become the most used mechanical valve in Japan and throughout the world. Because of its excellent durability, the SJM valve is typically used for relatively young patients, ${ }^{1}$ and its high performance and low event rate during long follow-ups have been reported previously (Table). ${ }^{1-4}$ The long-term outcomes are of specific interest, and cardiac surgeons are especially interested in the rates of thromboembolism, bleeding, reoperation, valve-related deaths, and valve-related complications (pannus formation, paravalvular leakage with hemolysis, valve thrombosis, and prosthetic valve endocarditis). According to the Society of Thoracic Surgeons/American Association for Thoracic Surgery (STS/AATS) guidelines for reporting mortality and morbidity after cardiac valve interventions, ${ }^{5,6}$ these complications should be evaluated using standardized valve-specific criteria. In particular, thromboembolism and bleeding, which have rates of development that are constant over time, should be evaluated by not only the actual rates but also the linearized rates.

\section{Article p 2380}

In this issue of the Journal, Minakata et $\mathrm{al}^{7}$ report the longest follow-up and multicenter high-volume analysis of aortic valve replacement using SJM mechanical valves in Japanese patients, which they performed in accordance with the STS/ AATS guidelines. The important findings from their report include linearized rates of thromboembolic events $(1.1 \%$ / patient-year), major bleeding events (1.0\%/patient-year), and aortic valve reoperation $(0.26 \% /$ patient-year). They also reported that valve-related death was the most common cause of death $(26.8 \%)$ and that the rates of freedom from valve-related death were $96.2 \%, 92.7 \%, 88.8 \%$, and $86.6 \%$ at $5,10,15$, and 20 years, respectively. These results compare favorably with the findings of previous reports, ${ }^{1-4}$ and were mainly affected by control of the prothrombin-international normalized ratio (PTINR). In the Japanese guidelines, the optimal range for PTINR during aortic mechanical valve replacement is 2.0-2.5 (vs. 2.0-3.0 for mitral mechanical valves and atrial fibrillation $[\mathrm{AF}]) .{ }^{8}$ Although the PT-INR target was the same as in the Japanese guidelines, the frequency of PT-INR control within the optimal range was not ascertained in this study. Unfortunately, PT-INR tends to drift, which can lead to thromboembolic and bleeding events. Furthermore, for very long periods of warfarin administration, it may be important to quantify the maintenance of the target PT-INR (eg, the time in the therapeutic range for PT-INR, which has been used for AF)., ${ }^{9,10}$ Moreover, the risk of thromboembolic and bleeding events varies according to age, and it is possible that the specific optimal range for PT-INR might vary according to the patient's age.

One complication of mechanical valve use is pannus formation during the follow-up. ${ }^{11}$ Although many factors are involved (eg, inflammation, thrombus formation, and turbulence around the valve), the precise cause of pannus formation has not been determined. ${ }^{12}$ Therefore, given that reoperations are rarely performed for mechanical valves, the frequency of pannus formation is very important. In this context, the SJM mechanical

\begin{tabular}{|c|c|c|c|}
\hline & $\begin{array}{c}\text { Nakano et al }{ }^{3} \\
(1994)\end{array}$ & $\begin{array}{c}\text { Aoyagi et al }{ }^{4} \\
(1994)\end{array}$ & $\begin{array}{c}\text { Minakata et } \mathrm{al}^{7} \\
(2015)\end{array}$ \\
\hline Patients ( $n$ ) & 425 & 178 & 801 \\
\hline Structural valve deterioration (\%/pt-year) & 0 & 0 & 0 \\
\hline Nonstructural dysfunction (\%/pt-year) & 0.16 & 0.4 & $0.02(\%)^{\ddagger}$ \\
\hline Valve thrombosis (\%/pt-year) & 0.05 & 0.14 & 0 \\
\hline Thromboembolism (\%/pt-year) & 1.35 & 0.85 & 1.1 \\
\hline Bleeding (\%/pt-year) & 0.1 & 0.4 & 1.0 \\
\hline Operated valve endocarditis (\%/pt-year) & 0.21 & 0.4 & $0.5(\%)^{\ddagger}$ \\
\hline
\end{tabular}

$\ddagger$ Actual rate.

The opinions expressed in this article are not necessarily those of the editors or of the Japanese Circulation Society.

Received September 23, 2015; accepted September 23, 2015; released online October 2, 2015

Department of Cardiovascular Surgery, Tokyo Women's Medical University, Medical Center East, Tokyo, Japan

Mailing address: Wataru Tatsuishi, MD, Department of Cardiovascular Surgery, Tokyo Women's Medical University, Medical Center East,

Nishiogu 2-1-10, Arakawa-ku, Tokyo 116-8567, Japan. E-mail: wataru0812_drt@ybb.ne.jp

ISSN-1346-9843 doi:10.1253/circj.CJ-15-1018

All rights are reserved to the Japanese Circulation Society. For permissions, please e-mail: cj@j-circ.or.jp 


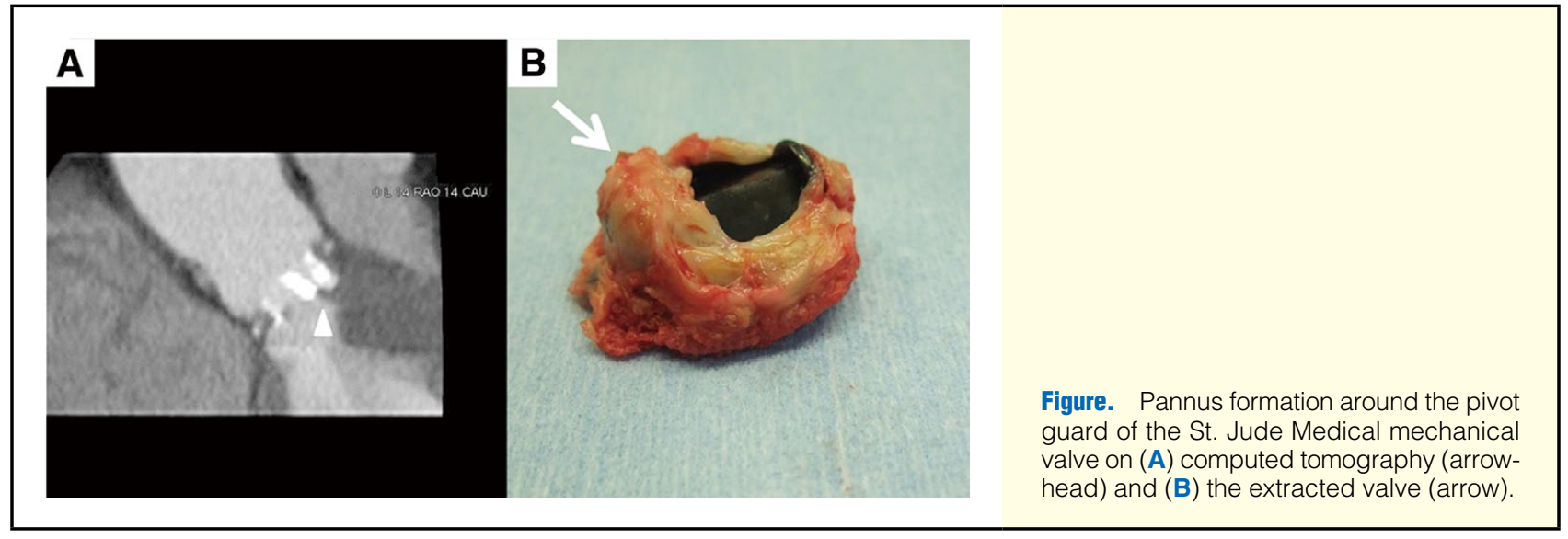

valve has a pivot guard that protrudes into the left ventricle outflow tract, which might cause pannus formation (Figure). Although the frequency of pannus formation in patients with SJM aortic valves is only $0.7-1.4 \%,{ }^{13}$ the protruding pivot guard has the potential for pannus formation, especially when it is near the mitral valve or septal wall. In this study, the most common reason for aortic valve reoperation was pannus formation $(1.5 \%)$, and the deaths from unknown causes might have been related to pannus formation. Therefore, additional data collection might be warranted.

The follow-up rate in their report is slightly lower (84.1\%) than in previous reports. ${ }^{2-4}$ However, given the recent enforcement of the Personal Information Protection Law, it might be difficult to analyze and collect information from patients over a long follow-up. Therefore, given the multicenter design, high-volume analysis, the data collection methods (data may have been collected from family doctors), and long follow-up period, this follow-up rate could be acceptable.

\section{References}

1. Emery RW, Krogh CC, Arom KV, Emery AM, Benyo-Albrecht K, Joyce LD, et al. The St. Jude Medical cardiac valve prosthesis: A 25-year experience with single valve replacement. Ann Thorac Surg 2005; 68: 776-782.

2. Toole JM, Stroud MR, Kratz JM, Crumbley AJ 3rd, Bradley SM, Crawford FA Jr, et al. Twenty-five year experience with the St. Jude medical mechanical valve prosthesis. Ann Thorac Surg 2010; 89: $1402-1409$.

3. Nakano K, Koyanagi H, Hashimoto A, Kitamura M, Endo M, Nagashima M, et al. Twelve years' experience with the St. Jude Medical valve prosthesis. Ann Thorac Surg 1994; 57: 697-702.

4. Aoyagi S, Oryoji A, Nishi Y, Tanaka K, Kosuga K, Oishi K. Longterm results of valve replacement with the St. Jude Medical valve. $J$ Thorac Cardiovasc Surg 1994; 108: 1021-1029.

5. Edmunds LH Jr, Clark RE, Cohn LH, Grunkemeier GL, Miller DC,
Weisel RD. Guidelines for reporting morbidity and mortality after cardiac valvular operations: Ad Hoc Liaison Committee for Standardizing Definitions of Prosthetic Heart Valve Morbidity of The American Association for Thoracic Surgery and The Society of Thoracic Surgeons. J Thorac Cardiovasc Surg 1996; 112: 708-711.

6. Akins CW, Miller DC, Turina MI, Kouchoukos NT, Blackstone EH, Grunkemeier GL, et al. Guidelines for reporting mortality and morbidity after cardiac valve interventions. J Thorac Cardiovasc Surg 2008; 135: 732-738.

7. Minakata K, Tanaka S, Okawa Y, Kaneko T, Okonogi S, Usui A, et al. Twenty-year outcomes of aortic valve replacement with St. Jude Medical mechanical valves in Japanese patients. Circ J 2015; 79: $2380-2388$.

8. Okita Y, Okada Y, Otsuji Y, Komeda M, Nakatani S, Matsuzaki M, et al. Guidelines for surgical and interventional treatment of valvular heart disease. Japanese Circulation Society, 2012. Available at http:// www.j-circ.or.jp/guideline/pdf/JCS2012_ookita_h.pdf (accessed August 31, 2015).

9. Okumura K, Komatsu T, Yamashita T, Okuyama Y, Harada M, Konta Y, et al. Time in the therapeutic range during warfarin therapy in Japanese patients with non-valvular atrial fibrillation: A multicenter study of its status and influential factors. Circ J 2011; 75: 2087-2094.

10. Okuyama Y, Matsuo M, Matsuo H, Sakaguchi Y, Takai H, Horiguchi $\mathrm{Y}$, et al. Introduction of point-of-care testing in Japanese outpatient clinics is associated with improvement in time in therapeutic range in anticoagulant-treated patients. Circ J 2014; 78: 1342-1348.

11. Ueda T, Teshima H, Fukunaga S, Aoyagi S, Tanaka H. Evaluation of prosthetic valve obstruction on electrocardiographically gated multidetector-row computed tomography: Identification of subprosthetic pannus in the aortic position. Circ J 2013; 77: 418-423.

12. Teshima H, Fukunaga S, Takaseya T, Tomoeda H, Akashi H, Aoyagi S. Obstruction of St. Jude medical valves in the aortic position: Plasma transforming growth factor type beta 1 in patients with pannus overgrowth. Artif Organs 2010; 34: 210-215.

13. Hurwitz SE, Waxman D, Hecht S. Acute failure of a St. Jude's prosthetic aortic valve: Large pannus formation masked by a small thrombus. J Am Soc Echocardiogr 2009; 22: 1086. e1 -e3, doi:10.1016/j. echo.2009.04.001. 